\section{Liquid ecstasy: a new kid on the dance floor}

\author{
J. RODGERS, C. H. ASHTON, E. GILVARRY and A. H. YOUNG
}

The use of recreational drugs in the UK is on the increase, as is the range of available substances. One relative newcomer to the drugs of misuse that is achieving popularity in the UK among 'ravers' and bodybuilders is gamma-hydroxybutyrate (GHB), also known as 'liquid ecstasy'.

\section{WHAT IS GHB?}

Gamma-hydroxybutyrate is an endogenous fatty acid found in every cell in the human body. In the brain it is widely distributed, reaching highest concentrations in the hypothalamus and basal ganglia (Gallimberti et al, 1989). It is available as a liquid or in powdered form and when taken by mouth it readily enters the brain and produces behavioural consequences that include anxiolytic, sedative and euphoric effects. It appears to have complex effects on both $\mathrm{GABA}_{\mathrm{A}}$ and $\mathrm{GABA}_{\mathrm{B}}$ receptors and has some actions similar to benzodiazepines, baclofen and alcohol (Barbaccia et al, 2002). The effects may result from potentiation of cerebral dopaminergic systems and there is evidence that the serotonin system also may be involved via stimulation of tissue serotonin turnover due to an increase in tryptophan transport (Gobaille et al, 2002). Gamma-hydroxybutyrate has been utilised in medical settings for a number of years to induce anaesthesia (Laborit, 1964), to aid with alcohol dependence and opioid withdrawal (Kam \& Yoong, 1998; Tarricone, 2000; Nicholson \& Balster, 2001) and as a treatment for sleep disorders (Mamelak, 1989; Chin et al, 1992).

\section{LEGAL STATUS}

During the 1980s GHB was popular in the USA as an over-the-counter food supplement. It enjoyed popularity among bodybuilders because it was believed to aid in fat reduction and muscle building
(Miotto et al, 2001). Gamma-hydroxybutyrate stimulates growth hormone release and activates the 'pentose pathway', which plays an important role in the synthesis of protein within the body. It also results in a protein-sparing effect, which reduces the rate at which the body breaks down its own proteins and it is these properties that are believed to underlie its ability to aid in bodybuilding and fat loss (Miotto et al, 2001). In 1990 the Food and Drug Administration banned over-the-counter sales because of the growing body of evidence of the potential for misuse. This was followed in March 2000 by the placing of the substance in Schedule 1 , making it illegal to possess or sell GHB without a licence in the USA. At the moment in the UK possession of GHB is not illegal, but manufacture and supply is illegal because the drug is a controlled substance under the Medicines Act 1968. Gamma-hydroxybutyrate became scheduled under the Misuse of Drugs Act in June 2003.

\section{ON THE DANCE FLOOR}

Reports from the USA, Australia and Europe indicate that GHB now is being consumed increasingly as a recreational drug (Colfax et al, 2001; Karch et al, 2001; Mattison et al, 2001; Miotto et al, 2001; Nicholson \& Balster, 2001; Whitten, 2001; Deveaux et al, 2002; Gross et al, 2002; Degenhardt et al, 2003). Degenhardt et al (2003), in a study of 76 Australian users, report that reasons for using the drug recreationally include the resultant feelings of euphoria, relaxation, increased sociability and loss of inhibition, as well as heightened sexual interest. There has been very little UK-based research into the use of GHB. One survey (Winstock et al, 2001) reports that $13 \%$ of a sample of 1151 respondents recruited via a dance-culture magazine (mean age of 23.9 years) reported using the drug. The mean age of first use of
GHB in this sample was 22.4 years. The effects of GHB were reported as including feelings of relaxation, a sense of well-being and very restful sleep, and its use is frequently associated with 'rave' or 'dance-party' settings, where it is used to aid 'comedown' following the use of stimulants. Consequently it is often taken along with or following the use of a range of other substances, including, most frequently, methylenedioxymethamphetamine (MDMA, Ecstasy), cocaine, lysergic acid diethylamide (LSD), cannabis and alcohol (Teter \& Guthrie, 2001; Degenhardt et al, 2002; Tong \& Boyer, 2002). Although interactions with other drugs of misuse are as yet unclear, research indicates that the concomitant use of alcohol interferes with GHB metabolism, preventing breakdown, raising blood concentrations and making respiratory arrest more likely (Karch et al, 2001). In the USA, GHB is popular among gay and bisexual men where it has been associated with increased sexual risk (Colfax et al, 2001; Mattison et $a l, 2001)$. A major concern is that the use of recreational drugs such as GHB could interact with agents commonly prescribed for patients with HIV. Antoniou \& Tseng (2002) report evidence of relative overdoses secondary to an interaction between GHB and MDMA and protease inhibitors, especially ritonavir.

\section{ACUTE SIDE-EFFECTS}

The increasing popularity of GHB is indicated by a sharp rise in the number of accident and emergency cases associated with it across Europe and in the USA (Espinosa et al, 2001; Marinetti et al, 2001; Whitten, 2001; Deveaux et al, 2002; Iten \& Oestreich, 2002; Miro et al, 2002). Adverse acute effects are wide ranging and include dizziness, blurred vision, hot/cold flushes, excess sweating, confusion, vomiting, loss of consciousness, tremors, blackouts and memory lapses, agitation and death (Galloway et al, 1997; Nicholson \& Balster, 2001; Degenhardt et al, 2002). In addition, evidence from both clinical and recreational settings indicates that GHB may induce seizures/fits (Dyer, 1991; Degenhardt et al, 2002) and coma (Espinosa et al, 2001). Adverse reactions have been reported at a wide variety of doses (between 2 and $30 \mathrm{~g}$; Chin et al, 1992), indicating variable individual responses to the drug. In addition the 
black-market manufacture of GHB inevitably leads to variations in potency; this, coupled with rapid onset and a steep doseresponse curve, places recreational users at particular and unpredictable risk of experiencing adverse effects and/or overdose. Gamma-hydroxybutyrate is rapidly metabolised into carbon dioxide and water with no residue of toxic metabolites detectable in urine 4-5 h after ingestion (Laborit, 1964). Consequently this makes it difficult to detect use of the substance during routine drug screens or following emergency admission.

\section{TOLERANCE AND WITHDRAWAL}

There is evidence that users develop tolerance to and physical dependence on GHB. Animal studies provide evidence for the development of tolerance and the presence of reinforcing/rewarding properties (Itzhak \& Ali, 2002). In humans a GHB withdrawal syndrome is reported to include insomnia, anxiety, tremor, confusion, delirium, hallucinations, tachycardia, hypertension, nausea, vomiting and diaphoresis (Galloway et al, 1997; Mahr et al, 2001; Miotto \& Roth, 2001; Miotto et al, 2001). Rosenberg et al (2003) report two cases of severe withdrawal delirium on a psychiatric unit in the USA. It is likely that, as the use of the drug increases, the psychiatric profession will have a greater role to play in the management of the consequences of use. Owing to its short duration of action, with a half-life of only 1-2 h (Scrima et al, 1990) and rapid elimination (Palatini et al, 1993), withdrawal symptoms appear rapidly following last administration (within 1-6h) and can persist for a number of weeks. Price (2000) reports the case of a 43-year-old male user who had been taking GHB for just over 2 years prior to referral for detoxification. The patient reported that over the period of use he had doubled his dosage and increased the frequency of ingestion from $15 \mathrm{ml}$ taken irregularly to $30 \mathrm{ml}$ every $3 \mathrm{~h}$ in order to obtain the desired psychoactive effects. Withdrawal symptoms were described as including anxiety, panic attacks and feelings of terror coupled with tremor and some autonomic features, for example diarrhoea. Detoxification was undertaken on an in-patient basis and involved a diazepam-reducing regime over a period of 11 days. In a similar case Addolorato et al (2001) describe a patient who was detoxified from GHB, again using diazepam.

\section{USE OF PRECURSORS}

There is now evidence that, as the legal status of GHB changes, users may turn to the use of precursors such as gammabutyrolactone (GBL) and 1,4-butanediol. These precursors, which remain widely available via the internet, are metabolised to GHB and pose the same risks to the user. Schneir et al (2001) report a case of withdrawal from GBL and 1,4-butanediol. The symptoms reported were nearly identical to those for GHB withdrawal and included hallucinations, tachycardia, tremor, nystagmus and diaphoresis. In a similar report Sivilotti et al (2001) give data from five patients who presented with severe GBL withdrawal syndrome that included paranoid delusions, hallucinations, psychosis and autonomic instability. Initial treatment with lorazepam proved to be ineffective, but subsequent treatment with pentobarbitol resulted in good recovery within 5 days. In the UK reports of misuse and withdrawal from these precursors should be expected.

\section{MODE OF ACTION}

The physiological mechanisms for withdrawal from GHB are not clearly understood. Research indicates that chronic use of GHB results in a down-regulation of inhibitory $\mathrm{GABA}_{\mathrm{A}}$ and $\mathrm{GABA}_{\mathrm{B}}$ and $\mathrm{GHB}$ receptors, resulting in the development of tolerance (Snead \& Nichols, 1987; Hechler et al, 1997). Cessation or a decrease in GHB use then results in a disinhibition of excitatory neurotransmitters (glutamate, norepinephrine and dopamine) and leads to withdrawal symptomatology. Similarities in terms of the psychoactive properties of use and of the pathophysiological effects of withdrawal have been reported between GHB and benzodiazepines (Miotto \& Roth, 2001). This suggests a common mechanism of action and Miotto \& Roth (2001) suggest that withdrawal from GHB involves loss of $\mathrm{GABA}_{\mathrm{A}^{-}}$and $\mathrm{GABA}_{\mathrm{B}^{-}}$ mediated inhibition. Further support for the role of GABA is presented by Carai et al (2001). Their results indicate that the sedative/hypnotic effects of GHB result from activation of $\mathrm{GABA}_{\mathrm{B}}$ receptors and that the behavioural depression of $\mathrm{GHB}$ was similar to that produced by baclofen, a $\mathrm{GABA}_{\mathrm{B}}$ agonist. In addition, the effect of both drugs was completely prevented by the administration of specific $\mathrm{GABA}_{B}$ antagonists SCH 50911 and CGP 46381.

\section{SUMMARY}

Gamma-hydroxybutyrate misuse is a relatively recent phenomenon and one that is far from clearly understood in terms of the likely cost to the user and to the wider community. There have been no systematic studies of the prevalence of dependency on GHB in the UK, nor do we have sufficient information relating to the demographic characteristics or the patterns of drug use among GHB users in this country. In addition, the mechanisms underlying the development of tolerance to and the rewarding effects of GHB, as well as any possible interaction effects with other drugs, are poorly understood. Similarly, although research has clearly demonstrated the acute risks of use, we know very little about long-term emotional, neuropsychological and behavioural costs. It is likely, however, that as use of the drug and its precursors increases in the UK the psychiatric profession increasingly will be faced with individuals experiencing the adverse effects of use and withdrawal. What is clear from the research so far is that misuse of GHB places the individual and the wider community at significant risk. Further studies of the use and misuse of this potentially harmful substance are clearly needed.

\section{DECLARATION OF INTEREST}

None.

\section{REFERENCES}

Addolorato, G., Caputo, F., Capristo, E., et al (200I) Diazepam in the treatment of GHB dependence (letter) British Journal of Psychiatry, I78, 183.

Antoniou, T. \& Tseng, A. L. (2002) Interactions between recreational drugs and antiretroviral agents. Annals of Pharmacotherapy, 36, 1598-1613.

Barbaccia, M. L., Colombo, G., Affricano, D., et al (2002) $G A B A_{B}$ receptor moderated increase in neurosteroids by gamma-hydroxybutyric acid. Neuropharmacology, 42, 782-791.

Carai, M. A. M., Colombo, G., Brunetti, G., et al (200I) Role of $G A B A_{B}$ receptors in the sedative/ hypnotic effect of gamma-hydroxybutyric acid. European Journal of Pharmacology, 428, 315-321.

Chin, M., Kreutzer, R. \& Dyer, J. (1992) Acute poisoning from gamma-hydroxybutyrate overdose. Annals of Emergency Medicine, 31, 716-722.

Colfax, G. N., Mansergh, G., Guzman, R., et al (2001) Drug use and sexual risk behaviour among gay and 
bisexual men who attend circuit parties: a venue-based comparison. Journal of Acquired Immune Deficiency Syndromes, 28, 373-379.

Degenhardt, L., Darke, S. \& Dillon, P. (2002) GHB use amongst Australians: characteristics, use patterns and associated harm. Drug and Alcohol Dependence, 67 89-94.

Degenhardt, L., Darke, S. \& Dillon, P. (2003) The prevalence and correlates of gamma-hydroxybutyrate (GHB) overdose among Australian users. Addiction, 98, 199-204.

Deveaux, M., Renet, S., Renet, V., et al (2002) gamma-hydroxybutyric acid (GHB) really used in raveparties and as a date rape drug in France? Acta Clinica Belgica, 57, 37-40.

Dyer, J. (199I) Gamma-hydroxybutyrate: a health food product producing coma and seizure like activity. American Journal of Emergency Medicine, 9, 321-324.

Espinosa, G., Miro, O., Nogue, S., et al (200I) Liquid ecstasy poisoning: study of 22 cases. Medicina Clinica, II7, 56-58.

Gallimberti, L., Canton, G., Gentile, N., et al (1989) Gamma-hydroxybutyric acid for treatment of alcohol withdrawal syndrome. Lancet, ii, 787-789.

Galloway, G., Frederick, S., Staggers, F., et al (1997) Gamma-hydroxybutyrate: an emerging drug of abuse that causes physical dependency. Addiction, 92, 89-96.

Gobaille, S., Schleef, C., Hechler, V., et al (2002) Gamma-hydroxybutyrate increases tryptophan availability and potentiates serotonin turnover in rat brain. Life Sciences, 70, 2101-2112.

Gross, S. R., Barrett, S. P., Shestowsky, J. S., et al (2002) Ecstasy and drug consumption patterns: a Canadian rave population study. Canadian Journal of Psychiatry, 47, 546-55।

Hechler, V., Ratomponirina, C. \& Maitre, M. (1997) Gamma-hydroxybutyrate conversion into GABA induces displacement of $G A B A_{B}$ binding that is blocked by valproate and ethosuximide. Journal of Pharmacology and Experimental Therapeutics, 28I, 753-760.

Iten, P. X. \& Oestreich, A. (2002) Gammahydroxybutyrate (GHB): a new generation of drugs from the chemical shelf. Chimia, 56, 91-95.

Itzhak, Y. \& Ali, S. F. (2002) Repeated administration of gamma-hydroxybutyric acid (GHB) to mice: assessment of the sedative and rewarding effects of GHB. Annals of the New York Academy of Sciences, 965 , $451-460$.

Kam, P. \& Yoong, F. (1998) Gamma-hydroxybutyric acid: an emerging recreational drug. Anaesthesia, $\mathbf{5 3}$ 1195-1198.

J. RODGERS, PhD, C. H. ASHTON, DOxon, School of Neurology, Neurobiology and Psychiatry, Faculty of Medical Sciences, University of Newcastle; E. GILVARRY, MRCPsych, Drug and Alcohol Service, Plummer Court, Newcastle upon Tyne; A. H. YOUNG, MRCPsych, School of Neurology, Neurobiology and Psychiatry, Faculty of Medical Sciences, University of Newcastle

Correspondence: Dr J. Rodgers, Ridley Building, University of Newcastle, Newcastle-upon-Tyne, Tyne and Wear NEI 4LP, UK. Tel: 0191 2227562; fax: 0191 2227520; e-mail: jacqui.rodgers@ncl.ac.uk

(First received 17 February 2003, final revision 4 August 2003, accepted I2 August 2003)

Karch, S. B., Stephens, B. G. \& Nazareno, G.v. (200I) GHB - Club drug or confusing artefact? American Journal of Forensic Medicine and Pathology, 22, 266-269.

Laborit, H. (1964) Sodium 4-hydroxybutyrate. International Journal of Neuropharmacology, 3, 433-452.

Mahr, G., Bishop, C. L. \& Orringer, D. J. (200I)

Prolonged withdrawal from extreme gammahydroxybutyrate (GHB) use. Psychosomatics, $\mathbf{4 5}$, 439-440.

Mamelak, M. (1989) Gamma-hydroxybutyrate: an endogenous regulator of energy metabolism. Neuroscience and Biobehavioral Review, 13, 187-198.

Marinetti, L. J., Isenschmid, D. S., Hepler, B. R., et al (200I) Response to the presence of gammahydroxybutyric acid (GHB) in postmortem biological fluids. Journal of Analytical Toxicology, 25, 356-357.

Mattison, A. M., Ross, M. W., Wolfson, T., et al (200I) Circuit party attendance, club drug use and unsafe sex in gay men. Journal of Substance Abuse, 13, 119-126.

Miotto, K. \& Roth, B. (200I) GHB Withdrawal Syndrome. Austin, TX: Texas Commission on Drug and Alcohol Abuse.

Miotto, K., Darakjian, J., Basch, J., et al (200I) Gamma-hydroxybutyric acid: patterns of use, effects and withdrawal. American journal on Addictions, $\mathbf{1 0}$. 232-24l.

Miro, O., Nogue, S., Espinosa, G., et al (2002) Trends in illicit drug emergencies: The emerging role of gammahydroxybutyrate. Journal of Toxicology - Clinical Toxicology, 40, 129-135.

Nicholson, K. L. \& Balster, R. L. (200I) GHB: a new and novel drug of abuse. Drug and Alcohol Dependence, 63, $1-22$

Palatini, P., Tedeschi, L., Frison, G., et al (1993) Dosedependent absorption and elimination of Gammahydroxybutyric acid in healthy volunteers. European Journal of Clinical Pharmacology, 45, 353-356.
Price, G. (2000) In-patient detoxification after GHB dependence. British Journal of Psychiatry (letter), 177, I8I.

Rosenberg, M. H., Deerfield, L. J. \& Baruch, E. M. (2003) Two cases of severe gamma-hydroxybutyrate withdrawal delerium on a psychiatric unit: recommendations for management. American Journal of Drug and Alcohol Abuse, 29, 487-496.

Schneir, A. B., Ly, H.T. \& Clark, R. F. (200I) A case of withdrawal from the GHB precursors gamma butyrolactone and I,4-butanediol. Journal of Emergency Medicine, 2I, 3I-33.

Scrima, L., Hartman, P. G., Johnson, F. H., et al (1990) The effects of gamma-hydroxybutyrate on the sleep of narcolepsy patients - a double blind study. Sleep, 13, 470-490.

Sivilotti, M. L. A., Burns, M. J., Aaron, C. K., et al (200I) Pentobarbital for severe gamma-butyrolactone withdrawal. Annals of Emergency Medicine, 38, 660-665.

Snead, O. C. \& Nichols, A. C. (1987) Gammahydroxybutyric acid binding sites: evidence for coupling to a chloride anion channel. Neuropharmacology, 26 I519-1523.

Tarricone, L. (2000) GHB treatment of alcohol and drug addiction. European Psychiatry, I5, 420.

Teter, C. J. \& Guthrie, S. K. (200I) A comprehensive review of MDMA and GHB: Two common club drugs. Pharmacotherapy, 2I, 1486-1513.

Tong, T. \& Boyer, E.W. (2002) Club drugs, smart drugs, raves and circuit parties: An overview of the club scene. Pediatric Emergency Care, 18, 216-218.

Whitten, L. (200I) Conference highlights increasing GHB abuse. NIDA Notes, 16, 10-11.

Winstock, A. R., Griffiths, P. \& Stewart, D. (200I) Drugs and the dance music scene: a survey of current drug use patterns amongst a sample of dance music enthusiasts in the UK. Drug and Alcohol Dependence, 64, 9-17. 